\title{
EFFECT OF FUNGICIDE TREATMENT ON DIELECTRIC PROPERTIES OF A VEGETABLE SEED (CAULIFLOWER)
}

\author{
Vishal Singh Chandel ${ }^{1}$, Rajiv Manohar ${ }^{2}$, Mohd. Shafi Khan ${ }^{3}$ \\ ${ }^{I}$ Department of Physics, Integral University, Lucknow, (U.P.), India-226026, \\ ${ }^{2}$ Department of Physics, Lucknow University, Lucknow, (U.P.), India-226007, \\ ${ }^{3}$ Department of Physics, AIET, Lucknow, (U.P.), India-226002,
}

\begin{abstract}
Effect of fungicides' (thiram, captan, carbendazim, bagalol) treatment on dielectric constant and dielectric loss of a vegetable seed, namely cauliflower at given moisture content and bulk density was examined using Hewlett-Packard (HP-4194A) impedance/gain phase analyzer over the frequency range of 0.01 to $10 \mathrm{MHz}$ and temperature range of $30-45^{\circ} \mathrm{C}$. Julabo (temperature controller, F-25, Germany) was used for keeping the temperature of seeds constant. Study showed that fungicide treatment cast considerable change in dielectric parameters namely the dielectric constant and dielectric loss.
\end{abstract}

Keywords-Dielectric constant, dielectric loss, moisture content, vegetable seed, fungicides

$* * *$

\section{INTRODUCTION}

The seed treatment is done to disinfect and disinfest them from seed born or soil-born pathogenic organism with the application of fungicide, insecticide, or combination of both. Vegetable seeds are treated with fungicides for control of fungal diseases arising from soil born organism, and pathogens that causes seed rots, damping of seed and seedling blights and root-rots, these treatments also save the seeds from many other infections. Fungicide treatment is also done to control the internally seed-born fungal pathogens e. g. loose smut fungi of vegetable seeds.

Seed treatments are not done only at the time of sowing but generally done at the time of harvesting to preserve the seed quality during transportation and storage and unit packaging. As enumerated in our earlier paper [1-3] the dielectric properties are well correlated with moisture content and bulk density of the material and can be used as indicator of these physical parameters of seeds. The dielectric based sensors use these models for the sensing of the moisture content and other physical parameter of seed lots and single kernel of seeds.

To investigate and assess the degree of impact of fungicides treatment on dielectric parameters, namely the dielectric constant and dielectric loss factor at different frequencies and temperature, four fungicides-Thiram (75\% WS), Carbendazim (50\% WP), Captan (50\% WP) and Bagalol [MEMC, $6 \%(\mathrm{Hg}), \mathrm{SD}$ ] were selected. The treatments were done by a common and versatile method-the slurry treatment method, described in details elsewhere [1]. These fungicides are used in treatments of various vegetable seeds for protection of seeds from various seed surface-born and soilborn diseases and other leaf and fruit blight and smuts. Other details of the fungicides have been published in our earlier paper [1]. Dielectric properties of many seeds have been explored a lot, but the effect of fungicides on dielectric properties has not yet been explored much, though different kinds of studies related with fungicides and seeds have been done in past [1-11].

\section{MATERIALS AND METHODS}

The experimentally determined values of dielectric constant ( $\left.\varepsilon^{\prime}\right)$, dielectric loss factor ( $\left.\varepsilon^{\prime \prime}\right)$, for reference (untreated) and fungicide treated samples for selected vegetable seed cauliflower at a given moisture content and bulk density, between the temperature range of $30-45^{\circ} \mathrm{C}$, and over the frequency range of $5 \mathrm{kHz}$ to $10 \mathrm{MHz}$ at different discrete frequencies: $5 \mathrm{kHz}, 10 \mathrm{kHz}, 30 \mathrm{kHz}, 100 \mathrm{kHz}, 300 \mathrm{kHz}, 1$ $\mathrm{MHz}, 3 \mathrm{MHz}$, and $10 \mathrm{MHz}$ have been evaluated.

In order to examine the impact of fungicide treatment on the above mentioned dielectric parameters, bar plots were drawn for dielectric constant and dielectric loss factor at $30^{\circ} \mathrm{C}$ of temperature with treated and non-treated (reference) seed sample of cauliflower.

Effects of fungicide treatment on vegetable seed cauliflower were examined at its initial moisture content $8.7 \%$ and normal bulk density 0.608 . Here the moisture content is given in percent and wet basis (w. b.), whereas the bulk density is in $\mathrm{gm} \mathrm{cm}^{-3}$. Density of sample in sample holder was kept constant to avoid the density valuation effect on dielectric parameters by consistent and systematic filling of seed kernels in sample holder to get natural course of settings.

Analysis of experimental results showed considerable effect of fungicides on dielectric parameters of cauliflower seed. 


\section{RESULTS AND DISCUSSION}

The treatment of fungicide brings considerable change in the values of dielectric parameters of cauliflower seed.

Both of the dielectric parameters, the dielectric constant and dielectric loss factor, showed positive and observable change with the treatments of fungicides for all the frequencies. The maximum change is seen with bagalol, followed by thiram and carbendazim. Least change in the values of the both parts $\varepsilon^{\prime}$ and $\varepsilon^{\prime \prime}$ of the complex permittivity is noticed with captan. The changes in dielectric constant over the given frequency range and $30{ }^{\circ} \mathrm{C}$, are found to lie in the range of 1.533 to 0.004 with thiram, 1.702 to 0.088 with carbendazim, 1.017 to 0.064 with captan, and 2.324 to 0.056 with bagalol, whereas the changes in dielectric loss factor are found to lie in the range of 0.842 to $0.111,0.728$ to $0.071,0.998$ to 0.055 , and 1.669 to 0.141 , with corresponding fungicide respectively [1].

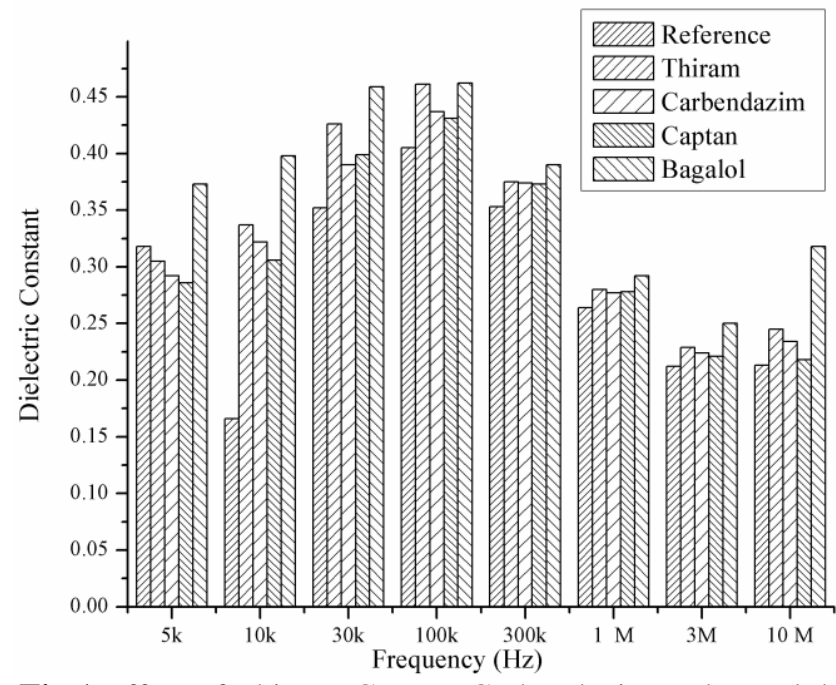

Fig.1 Effect of Thiram, Captan, Carbendazim and Bagalol treatment on dielectric constant of cauliflower at indicated frequencies and $30^{\circ} \mathrm{C}$.

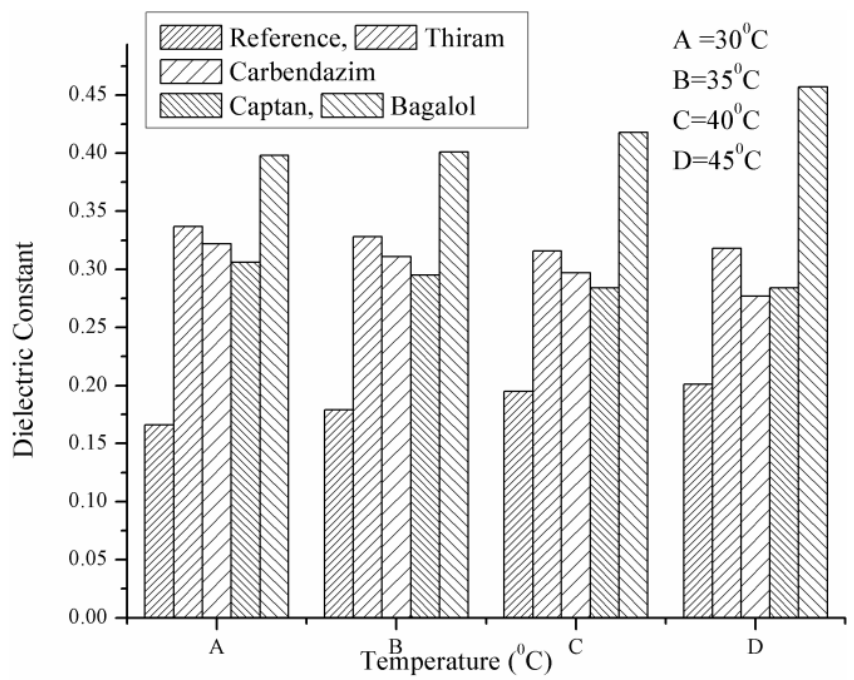

Fig.2 Effect of Thiram, Captan, Carbendazim and Bagalol treatment on dielectric constant of cauliflower at indicated Temperatures at $10 \mathrm{kHz}$.

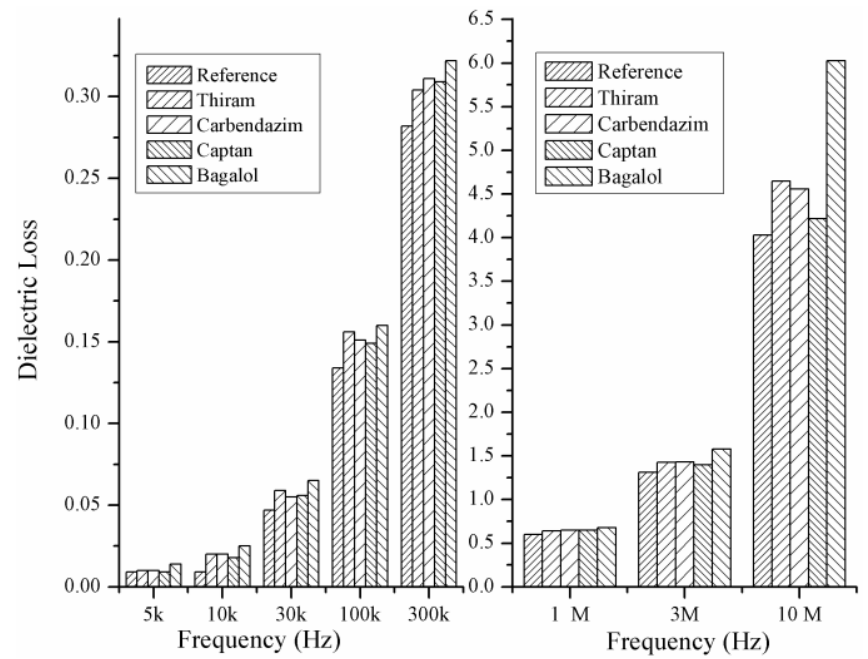

Fig.3 Effect of Thiram, Captan, Carbendazim and Bagalol treatment on dielectric loss of cauliflower at indicated frequencies and $30^{\circ} \mathrm{C}$.

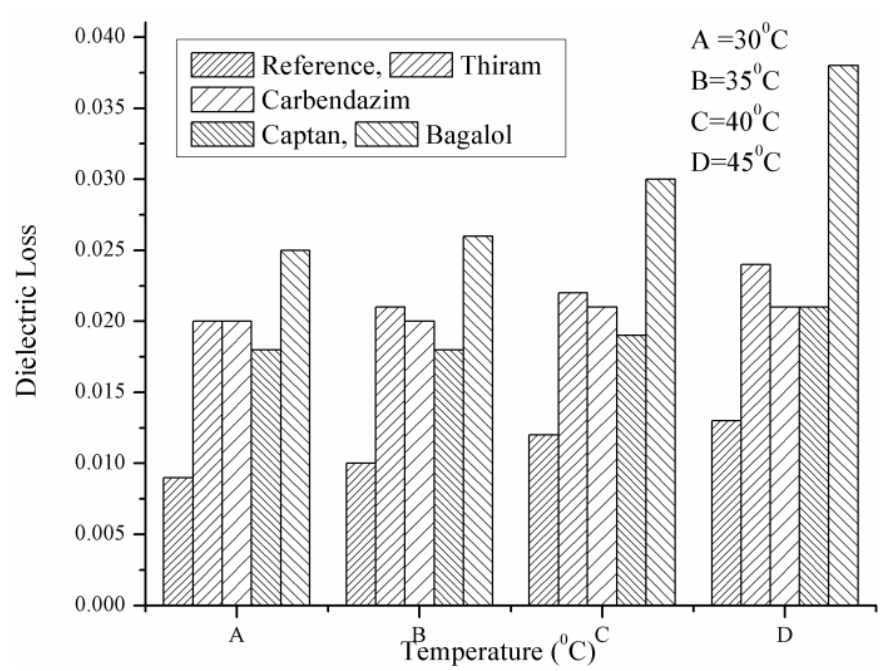

Fig.4 Effect of Thiram, Captan, Carbendazim and Bagalol treatment on dielectric loss of cauliflower at indicated Temperatures at $10 \mathrm{kHz}$.

\section{CONCLUSIONS}

The analysis of effect of fungicide treatment on dielectric parameters of vegetable seed revealed that different types of fungicides cast different amount of change in different dielectric parameters of vegetable seed. The changes induced by the fungicides are quite high and cannot be ignored when precise and accurate measurements are needed for the sensing of extensive physical properties of seed and for other applications useful in agricultural technologies.

A change in dielectric parameters of same seed when treated with different types of fungicides is obvious from difference in chemical composition and electrical and dielectric properties of fungicides. The physical and chemical properties of seed are also having their own contribution in altering the dielectric parameters when fungicide treatments are done. 


\section{REFERENCES}

[1] V. S. Chandel, A. Rahman, J. P. Shukla and R. Manohar. Effect of Fungicide Treatment on Dielectric Properties of Few Coarse- Cereals Over the Frequency Range 0.01 to $10 \mathrm{MHz}$, Walailak J Sci \& Tech 2012; 9(3): 217-227.

[2] M. S. Khan, V. S. Chandel, R. Manohar, and J. P. Shukla, Study of Dielectric Properties of Fenugreek Seeds (Trigonella Foenum Graecum), Plant Breeding and Seed Science, 2012; 66:17-28. (Accepted) DOI: 10.2478/v10129-011-0054-6.

[3] V. S. Chandel, M. S. Khan and R. Manohar, Dielectric Study Of Medicinal Seed: Black Seed (Nigella Sativa L), Asian Journal of Physical Sciences, 2012: 1(2), 114.

[4] C. M. Tu, Effect of fungicidal seed treatments on alfalfa growth and modulation by rhizobium meliloti. Chemosphere, 1981; 10: 127-34.

[5] C. M. Tu. Effects of some pesticides on rhizobium japonicum and on the seed germination and pathogens of soybean. Chemosphere, 1982; 11(10), 1027-33.

[6] L. R. Rathod, M. D. Jadhav, D. S. Kanse, D. P. Patil, S. D. Gulhane and P. S Deshmukh. Effects of fungicides on seed borne pathogen of groundnut. International Journal of Advanced Biotech. and Research. 2010; 1(1), 17-20.

[7] S.N. Manjunatha, R. Hunje, B.S Vyakaranahal and I.K Kalappanavar. Effect of seed coating with polymer, fungicide and containers on seed quality of chilli during storage. Karnataka J. Agric. Sci., 2008; 21(2), 270-73.

[8] B. O. Basavaraj, N.K.B Patil, B.S Vyakarnahal, N.Basavaraj, B.B. Channappagoudar and R. Hunje. Effect of fungicide and polymer film coating on storability of onion seeds. Karnataka J. Agric. Sci., 2008; 21(2): 212-218.

[9] G. Saeidi and A.A.M. Mirik. Fungicide seed treatment and seed colour effects on seed vigour and emergence in flax. International Journal of Agriculture \& Biology, 2006; 8(6), 732-735.

[10] S.P. Singh, P. Kumar, R. Manohar and J.P. Shukla. Dielectric properties of some oil seeds at different concentration of moisture content and micro-fertilizer. International Journal of Agricultural Research, 2006; 1(3), 293-304.

[11] M.S. Khan and V.S. Chandel. Study of conductivity and penetration depth of argemone seeds at different concentrations of moisture. J. Pure Apll. \& Ind. Phy, 2011; 1(2), 153-161. 